\title{
A PRODUÇÃO DE ROCHAS ORNAMENTAIS NO NOROESTE DO ESTADO DO RIO DE JANEIRO: SANTO ANTÔNIO DE PÁDUA E ITALVA
}

\author{
Carolina Pereira Silvestre \\ Doutoranda em Dinâmica dos Oceanos e da Terra - UFF \\ cps_silvestre@hotmail.com \\ Luiz Carlos Bertolino \\ Centro de Tecnologia Mineral - COAM-RJ - Prof. Adj. Depto. Geografia UERJ-FFP \\ lcbertolino@uol.com.br \\ Viviane Pires Melo \\ Graduada em Geografia UERJ/FFP \\ v.pm.26@hotmail.com
}

Artigo recebido em 18/10/2013 e aceito para publicação em 23/02/2014

DOI:10.12957/tamoios.2014.7858

RESUMO

O Noroeste Fluminense é o principal produtor de rochas ornamentais do estado. Os municípios de Santo Antônio de Pádua e Italva tem na produção de rochas ornamentais a base para o seu desenvolvimento socioeconômico. Este estudo objetiva caracterizar o processo de produção de rochas, identificando e caracterizando os principais problemas e soluções adotadas para solucioná-los. A metodologia empregada consistiu na realização de trabalhos de campo nas pedreiras, serrarias e instituições diretamente ligadas ao setor; e entrevistas com representantes de diferentes segmentos deste setor produtivo. Os resultados indicam que existem cerca de 300 microempresas empregando aproximadamente 6.000 pessoas, destas somente 140 são associadas ao sindicato local. Alguns empreendimentos ilegais causam desmatamentos e descartam rejeitos em locais impróprios, causando danos ao meio ambiente. Em conjunto, instituições públicas e privadas têm adotado medidas para sanar tais problemas, entre elas: assinatura do TAC (Termo de Ajustamento de Conduta), construção da empresa Argamil e instalação de tanques de decantação. Essas ações objetivam minimizar os impactos e proporcionar um desenvolvimento sustentável a região.

Palavras-chaves: rochas ornamentais; Santo Antônio de Pádua; Italva; impactos socioeconômicos.

ABSTRACT The Northwest of Rio de Janeiro State is the main producer of ornamental stones of the state. The socioeconomic development of the municipalities of Santo Antonio de Padua and Italva is based on the production of these ornamental rocks. The present study aims to characterize the mineral production process, identifying and characterizing the main problems and solutions adopted to solve them. The methodology consisted of field works in the stone quarries, sawmills and institutions directly linked to the sector, and interviews with representatives of different segments of the productive sector. The results indicate that there are approximately 300 microenterprises employing approximately 6,000 people, only 140 of these are associated with the local syndicate. Some illegal undertakings deforest and discard waste in inappropriate places causing damage to the environment. Together, public and private institutions have taken measures in order to remedy such problems, including: signing the CAC (Contract to Adjustment of Conduct), Argamil company construction and installation of decantation ponds. These actions aim to minimize impacts and provide a sustainable development in the region.

Keywords: ornamental stones; Santo Antônio de Pádua; Italva; socioeconomic impacts. 


\section{INTRODUÇÃO}

Durante a história da humanidade as rochas já foram utilizadas para a fabricação de instrumentos domésticos, armas de caça e de defesa, além de abrigo em forma de cavernas. No mundo contemporâneo são usadas na construção civil, fabricação de pré-moldados, como manilhas e bloquetes, pavimentação de ruas e no revestimento de construções, dando-lhes uma função ornamental.

As rochas ornamentais e de revestimento compreendem os tipos litológicos que podem ser extraídos em blocos ou placas, cortados em formas variadas e beneficiados por meio de esquadrejamento, polimento, etc. Podem ser utilizados em esculturas, tampos e pés de mesa, arte funerária, revestimentos internos e externos de paredes, pisos, entre outros. De modo geral, são comercialmente divididas em três categorias: mármores, definido como rochas metamórficas formadas principalmente por calcita $\left(\mathrm{CaCO}_{3}\right)$ e dolomita $(\mathrm{Ca}, \mathrm{Mg}) \mathrm{CO}_{3}$; granito, abrange o grupo das rochas silicáticas (ricas em sílica e alumínio - gnaisses, migmatitos, etc.) e pedras decorativas, rochas de processamento simples e de uso direto na construção civil em geral ou, ainda, como adornos e/ou peças decorativas in natura, trabalhadas em diversas formas. São exemplos destas: ardósias, milonitos-gnaisse (Pedras Madeira e Paduana), calcários etc. (DRM-RJ, 2012).

A cadeia produtiva de rochas ornamentais é composta por dois segmentos, as pedreiras e as serrarias. As pedreiras ou lavras são frentes de exploração a céu aberto que promovem o desmonte de rochas através de bancadas. $\mathrm{E}$ as serrarias compreendem as instalações que contenham uma ou mais máquinas de disco diamantado para transformar e beneficiar o produto extraído na pedreira (MEDINA et al., 2003).

O Brasil atualmente ocupa a quarta posição no ranking mundial com produção de 8,9 milhões de toneladas e sexta posição entre os maiores exportadores de rochas do mundo (DRM-RJ, 2012). Entre os maiores produtores nacionais estão os estados do Espírito Santo, Minas Gerais e Rio de Janeiro (MARTINEZ \& HEIDER, 2012). O Noroeste Fluminense é o principal pólo mineral do estado, composto por cerca de 300 microempresas, que empregam em torno de seis mil pessoas (PEITER et al., 2011). Os municípios de Santo Antônio de Pádua e Italva foram escolhidos para este estudo por se destacarem na produção do granulito milonitizado e do mármore, respectivamente. Objetivando analisar a forma de exploração de rochas ornamentais, identificando e caracterizando os principais problemas de natureza socioeconômica e ambiental e as iniciativas adotadas para solucioná-los. Assim como, verificar o tipo de material produzido e avaliar a importância socioeconômica dessa atividade.

\section{ÁREA DE ESTUDO}

A área de estudo corresponde a Região Noroeste Fluminense, representada pelos municípios de Santo Antônio de Pádua e Italva (Figura 1). O município de Santo Antônio de Pádua foi criado em 1850, possui área territorial de $603 \mathrm{~km}^{2}$ divididos em nove distritos. De acordo com o Censo de 2010 a população é de 40.589 habitantes (IBGE, 2010). A economia do município gira em torno das pequenas e médias indústrias que se dedicam a produção de papel, argamassa, asfalto, café, entre outros; agropecuária; extração e beneficiamento de rochas ornamentais; e de inúmeros estabelecimentos comerciais.

O município de Italva foi criado em 1986, possui área territorial de $294 \mathrm{~km}^{2}$ dividido em quatro distritos e uma população de 14.063 habitantes (IBGE, 2010). Inicialmente, a base da economia era a agropecuária e a exploração mineral, maior fonte de arrecadação de impostos. Praticamente toda a economia do município 
sustentava-se na produção do mármore, cimento, cal e calcário. Seu nome faz referência à abundância de calcário existente em seu território, através da junção das palavras de origem tupi "ita" que significa pedra com "alva", que quer dizer branca. As empresas de extração eram tão importantes para o município que deram nomes aos lugares, como Guarnieri, Cimento Paraíso, etc. De acordo com a Prefeitura de Italva, com o declínio da exploração mineral, a pecuária, a agricultura, o comércio varejista e as confecções são as atividades econômicas mais importantes, embora oferecendo poucas oportunidades de emprego.

Figura 1: Mapa de localização dos municípios de Santo Antônio de Pádua e Italva. Fonte: Base cartográfica do

IBGE, 2012.

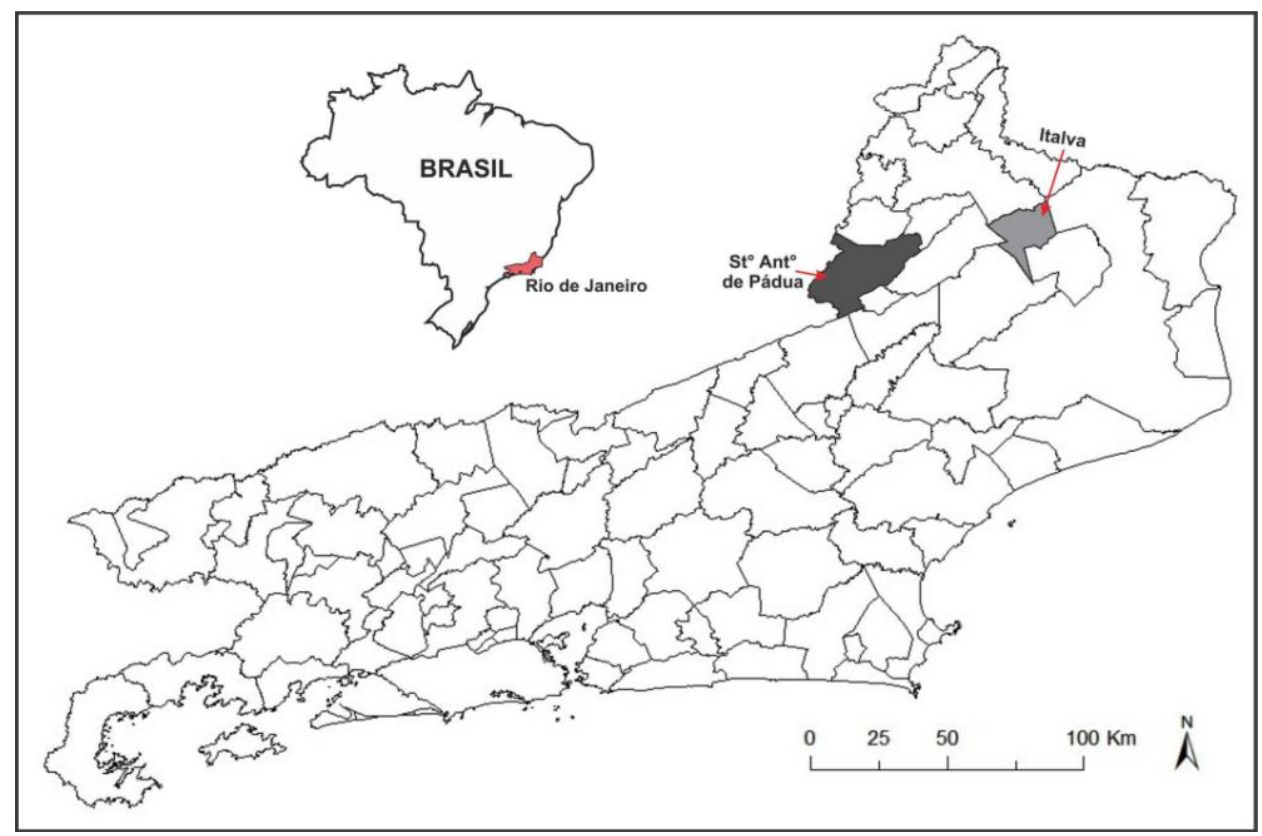

\section{PRODUÇÃO DE ROCHAS ORNAMENTAIS NO BRASIL}

O Brasil é um dos grandes produtores e exportadores mundiais de rochas ornamentais e de revestimento (CHIODI FILHO, 2002), abrangendo 1000 variedades comerciais nos mercados interno e externo, exploradas em cerca de 1.500 frentes ativas de lavra a céu aberto e em maciço ou matacões (CHIODI FILHO \& CHIODI, 2009). De acordo com estimativa da Abirochas (Associação Brasileira da Indústria de Rochas Ornamentais), a produção brasileira foi de $8,9 \mathrm{Mt}$ (milhões de toneladas) em 2010. A região sudeste deteve 65,2\% desta produção, a nordeste, $24,7 \%$ e as regiões sul, centro-oeste e norte contribuíram com um total de $10 \%$. Os estados do Espírito Santo, Minas Gerais, Bahia, Ceará, Paraná, Rio de Janeiro, Goiás e Paraíba respondem por cerca de 90\% da produção nacional (MARTINEZ \& HEIDER, 2012).

As exportações brasileiras de rochas ornamentais superaram as expectativas desde a década de 1990 até 2006, quando ultrapassaram US\$ 1 bilhão e 2,5 milhões t/ano. No ano de 2007, o país foi o $2^{\circ}$ maior exportador de rochas silicáticas brutas e de ardósia, $5^{\circ}$ maior exportador de rochas processadas especiais e $7^{\circ}$ em rochas processadas simples. A partir de 2008, com a crise do mercado imobiliário dos EUA (principal importador), a retração econômica mundial e o aumento da participação chinesa no mercado internacional, o comércio externo tornou-se mais restrito para esse produto. Com isso, o mercado interno passou a ser uma boa alternativa para a 
manutenção do parque de beneficiamento e acabamento expressivo no Sudeste e até no Nordeste (CHIODI FILHO \& CHIODI, 2009).

Porém, a participação brasileira no mercado internacional de rochas processadas ainda é limitada, muito inferior a China e a Índia, nossos maiores concorrentes. Mesmo com tanta potencialidade, a grande diversidade de tipos de rochas, os problemas políticos e as dificuldades técnicas vinculadas à exploração e beneficiamento fazem com que o setor no Brasil não potencialize o bastante a sua vocação (VARGAS et al., 2001). O parque industrial brasileiro de beneficiamento encontra-se tecnologicamente defasado, sobretudo pelo uso de máquinas e equipamentos antigos. Sua modernização poderá ser viabilizada através da adequação e automação das máquinas e equipamentos já instalados e com até 10 anos de uso, e, sobretudo através da aquisição de bens de capital tecnologicamente atualizados (PEITER \& CHIODI FILHO, 2001).

\section{EXPLORAÇÃO DE ROCHAS ORNAMENTAIS NO ESTADO DO RIO DE JANEIRO}

O Estado do Rio de Janeiro caracteriza-se pela diversidade de recursos minerais, especialmente os nãometálicos como o petróleo, gás e rochas, destinadas principalmente a construção civil (DRM-RJ, 2012). Atualmente ocupa o $5^{\circ}$ lugar entre os principais estados produtores de rochas ornamentais, contribuindo com 260.000 t/ano. Os principais tipos de rochas exploradas são o granito, o mármore e Pedra Miracema. Possui um parque de processamento de rochas ornamentais com 1.500 empresas e mais de 11 mil empregos formais distribuídos na região metropolitana da cidade do Rio de Janeiro e nas regiões Norte e Noroeste (ZEPEDA, 2009).

Da mesma forma que o Brasil, na década de 1990, o estado do Rio de Janeiro passou por um período de crescimento na produção de rochas processadas (PEITER \& CHIODI FILHO, 2001). Contudo, as mudanças implementadas pelos governos na política tributária, ambiental e de uso e ocupação do solo gerou um período de crise. Essa situação vem sendo superada gradativamente e está relacionada às melhorias que ocorreram nos tributos, na infraestrutura portuária, de transporte e de serviços. Atualmente, as empresas localizadas no estado do Rio de Janeiro, produtoras de mármore e granito, estão utilizando aproximadamente $33 \%$ da capacidade de suas pedreiras, e em torno de 50\% de suas serrarias e marmorarias (MARGUERON \& MELLO, 2005).

Em razão do destaque que a exploração de rochas ornamentais alcançou desde o final dos anos de 1990, já é possível identificar mudanças importantes no setor. Nos últimos anos, a gestão de recursos naturais tem-se orientado pelos princípios do desenvolvimento sustentável e é fundamental adequar-se a ele para ampliar o mercado consumidor (PEITER, 2002).

\section{EXPLORAÇÃO DE ROCHAS ORNAMENTAIS NO NOROESTE FLUMINENSE}

O Noroeste Fluminense é o principal pólo de exploração de rochas do estado do Rio de Janeiro, composto por mais de 200 pedreiras e 100 serrarias em operação, que geram cerca de seis mil empregos diretos e indiretos (PEITER et al., 2011). A produção mineral da região se concentra nas lavras de Santo Antônio de Pádua, Italva e Itaperuna (ERTHAL et al., 2008). Cuja capacidade é limitada pelos processos de exploração e beneficiamento rudimentares e impactos ambientais causados por esta atividade (PEITER et al., 2011).

No ano de 1998 foi criado o SINDGNAISSES (Sindicato de Extração e Aparelhamento de Gnaisses no 
Noroeste do Estado do Rio de Janeiro) para estimular o desenvolvimento do setor de rochas ornamentais e representar os interesses dos seus associados. Sua base territorial compreende os municípios de Santo Antônio de Pádua, Aperibé, Bom Jesus do Itabapoana, Cambuci, Italva, Itaocara, Itaperuna, Laje do Muriaé, Miracema, Natividade, Porciúncula, São José de Ubá e Varre-Sai. Com Sede e Foro no Município de Santo Antônio de Pádua e sem fins lucrativos (Estatuto do SINDGNAISSES, 1998).

A assinatura do TAC (Termo de Ajuste de Conduta Coletivo) em 2004 para a obtenção da Licença de Operação das pedreiras e serrarias foi promovido pelo DRM-RJ (Departamento de Recursos Minerais) e INEA (Instituto Estadual do Ambiente) (Termo de Compromisso de Ajustamento de Conduta Coletivo, 2004). A criação do Arranjo Produtivo Local de Rochas Ornamentais (APL), formado pelo conjunto de empresas envolvidas nos diversos estágios da produção, pretende implementar estratégias para dinamizar e integrar o setor, buscando eficiência produtiva, geração de emprego, trabalho e renda, estabilidade social e reforço da formalidade, através de uma rede formada por pessoas físicas e diversas organizações (BRITTO et al., 2010).

\section{SANTO ANTÔNIO DE PÁDUA}

O município de Santo Antônio de Pádua se destaca como um Parque Produtor de Rochas Ornamentais em posição privilegiada no estado, isso se deve a quantidade significativa de pedreiras e expressiva variedade litológica (BAPTISTA FILHO \& TANAKA, 2002; ALMEIDA et al., 1998). A expansão da atividade mineradora ocorreu entre as décadas de 1970 e 1980, incentivada pela utilização dessas rochas na construção civil e pelo surgimento de serrarias que faziam o acabamento de rochas serrando-as em vários tamanhos. (CARVALHO et al., 2002). Apesar da exploração de rochas ornamentais ter crescido bastante nos últimos anos, as técnicas de extração ainda são rudimentares comprometendo a produtividade local e a competitividade nacional e internacional do setor, além de acentuar o desgaste ambiental e os problemas de saúde na região (PEITER et al., 2003).

O granulito milonitizado, principal rocha explorada, é diferenciado comercialmente por suas características físicas mais marcantes. Os principais problemas inerentes a essa atividade são: o manuseio inadequado e o uso exagerado dos explosivos; perda de material, em torno de $80 \%$ na lavra e no beneficiamento; efluente final das serrarias com aspecto leitoso; a falta de planejamento técnico-econômico e de equipamentos de segurança para os trabalhadores (ALMEIDA et al., 1998).

Buscando minimizar esses problemas o SEBRAE-RJ (Serviço Brasileiro de Apoio às Micro e Pequenas Empresas) e o CETEM (Centro de Tecnologia Mineral) desenvolveram as seguintes soluções: assistência técnica e de segurança aos mineradores; conceitos básicos de mineração e assistência técnica às diversas pedreiras e serrarias para minimizar as perdas e reaproveitar os resíduos; ensinamentos sobre a legislação mineral, ambiental e trabalhista; e estudos para a melhoria dos efluentes gerados nas serrarias.

Com essas iniciativas o processo de reutilização de resíduos das rochas foi implantado de forma pioneira e chegou até mesmo a conquistar prêmios nos anos de 2005, 2006 e 2008. Foi inaugurada uma fábrica de argamassa que emprega tecnologia desenvolvida pelo CETEM e pelo INT (Instituto Nacional de Tecnologia) e produz argamassa industrial a partir dos rejeitos fornecidos pelos empresários locais (RIBEIRO et al., 2007). A tecnologia empregada permite reutilizar $95 \%$ da água através do circuito fechado nas serrarias. O processo de "produção limpa" reduz os danos ambientais e proporciona o melhor gerenciamento dos recursos regionais 
(CARVALHO, 2002). Recentemente, as variedades de rochas exploradas no município receberam indicação geográfica, selo de qualidade que agrega valor ao produto (DRM-RJ, 2010).

\section{ITALVA}

O município de Italva possui o maior potencial para a extração de mármore ornamental do estado do Rio de Janeiro (ERTHAL et al., 2008). O mesmo ocorre em relação à extração de minérios e a produção de cimento e de cal. As indústrias que há poucas décadas tornavam Italva um local relativamente próspero e com boas oportunidades entraram em colapso, devido à estagnação econômica dos setores mineral e da construção civil, acarretando o aumento do desemprego e perda de arrecadação. Junto a Prefeitura o setor mineral era o que mais gerava postos de trabalho (FONTES et al., 2002).

Atualmente, segundo dados da Prefeitura de Italva, a principal economia do município é a pecuária e a agricultura, ganhando destaque o comércio varejista e as confecções locais. Dados do IBGE (2009) apontam para o setor de serviços como sendo o principal responsável por mover a economia do município, ficando em segunda posição a indústria e em terceiro a agropecuária.

$\mathrm{Na}$ tentativa de superar esses problemas e dar novo dinamismo ao município houve a implantação de um programa de Estratégias de Desenvolvimento Local Integrado e Sustentável (DLIS). O DLIS propõe a construção de rumos alternativos através de um planejamento integrado e participativo, baseado na participação e gestão dos diversos seguimentos diretamente envolvidos com a atividade mineradora (FONTES et al., 2002). Entretanto, atualmente o mármore não está sendo extraído para fins ornamentais. A mineração se concentra na exploração de dolomita e calcita, usadas como corretivo de solo e pó Industrial.

\section{GEOLOGIA REGIONAL}

$\mathrm{O}$ estado do Rio de Janeiro é formado por rochas ígneas, sedimentares e metamórficas. As rochas metamórficas representam mais de $80 \%$ do seu território com idades que variam de 500 milhões até 2 bilhões de anos. Também predominam no Noroeste Fluminense e são encontradas como rochas metamórficas ortoderivadas e paraderivadas. As ortoderivadas têm origem no metamorfismo de rochas ígneas e são as mais abundantes, principalmente através dos chamados ortognaisses, que apresenta composição semelhante a do granito, porém com estrutura planar bem desenvolvida, como por exemplo, as rochas exploradas em Santo Antônio de Pádua. As paraderivadas, ou metassedimentares, formam-se a partir do metamorfismo das rochas sedimentares, as mais comuns no estado são os paragnaisses, que possuem minerais típicos de metamorfismo sobre sedimentos, como a sillimanita e a granada. As rochas metassedimentares correspondem aos mármores de Cantagalo e Italva, que indicam ter havido um grande depósito de sedimentos carbonáticos associado a um ambiente marinho na região em torno de 1 bilhão A.P. (DRM-RJ, 2008).

Litologicamente Santo Antônio de Pádua é constituído por gnaisses, quartzitos e granulitos, que pertence ao Complexo Charnockítico (BAPTISTA FILHO \& TANAKA, 2002a). O granulito milonitizado ocorre em duas serras, a do Bonfim e a do Catete, que margeiam a BR-393 (BOCLIN, 2009). Na Serra do Bonfim são exploradas principalmente rochas milonitizadas de cor cinza, conhecidas como Pedra Miracema (BAPTISTA FILHO \& TANAKA, 2002). As variações litológicas permitiram a comercialização dos seguintes 
tipos de rochas: Granito Olho-de-pombo, Granito Pinta Rosa, e Granito Fino (PEITER et al., 2003). As rochas exploradas na Serra do Catete também são miloníticas, comercialmente conhecidas como Pedra Madeira e encontradas nas seguintes variedades: Pedra Madeira Branca, Pedra Madeira Amarela e Pedra Madeira Rosa (BAPTISTA FILHO \& TANAKA, 2002).

O mármore de Italva está presente nas unidades do Domínio Italva de origem Pré-Cambriana com orientação em faixas NE-SW. Dentre as oito unidades que constituem esse domínio as que estão associadas à exploração mineral são: Unidade São Joaquim, com mármore puro de granulometria média a grossa, homogêneo, com níveis ricos em grafita e intercalações de anfibolitos; Unidade Italva com metamorfitos (hornblenda - biotita - plagioclásio gnaisses) de coloração cinza, granulação média, textura granoblástica, bandados, anfibolitos, quartzitos e calciossilicatadas; e Unidade São João do Paraíso, formada por migmatitos de coloração cinza-azulada, exibindo estrutura dobrada, flebítica e estromática, constituídos de granada, hornblenda, biotita, plagioclásio, entre outros (BATISTA et al., 2010).

\section{METODOLOGIA}

O estudo sobre a atividade mineradora no Noroeste Fluminense iniciou-se com o levantamento bibliográfico nas instituições competentes ligadas ao setor de mineração, como o CETEM, DRM-RJ, DNPM (Departamento Nacional de Produção Mineral), Prefeituras Municipais, entre outros.

Em seguida foram realizadas visitas às instituições diretamente relacionadas ao setor, escolhidas de acordo com seu porte e facilidade de acesso, e entrevistas com seus responsáveis em ambos os municípios. Em Santo Antônio de Pádua foram: a pedreira e serraria Map’s Pedras e a serraria Comércio de Pedras Paraíso; antigos trabalhadores do setor; o SINDGNAISSES; a Secretaria Municipal do Meio Ambiente; a empresa ARGAMIL; a GeoEstação, prestadora de consultoria geológica e ambiental, e o SEBRAE, que tem atuado de forma intensa na região. Em Italva foram visitadas a serraria Indústria de Mármore Italva Ltda. (IMIL) e as seguintes pedreiras: Enrico Guarneri Indústria e Comércio S.A., Indústria e Comércio de Cal Maravilha Ltda., Calpar Italva Mineração Ltda. e Pedreira de Calcário Ita Branca Ltda. Também foram entrevistados 20 moradores que residem próximo a empresa Enrico Guarneri Indústria e Comércio S.A. Para as entrevistas foram elaborados questionários com objetivo de coletar informações relacionadas ao desenvolvimento da atividade mineradora nesses municípios. Os dados apresentados são referentes ao ano de 2010.

\section{RESULTADOS E DISCUSSÕES}

Desde o início das atividades a exploração de rochas ornamentais no Noroeste Fluminense causa danos ao meio ambiente e aos próprios trabalhadores. A escolha dos locais destinados à exploração geralmente é feita sem nenhum critério e isso eventualmente implicava em um baixo aproveitamento do potencial dessas áreas e o abandono das mesmas. A ilegalidade e o modelo de produção deficiente do ponto de vista tecnológico são alguns dos principais entraves para o seu desenvolvimento atualmente. Esse quadro começou a melhorar após intervenções feitas pelo Ministério Público e instituições competentes, num movimento pela legalização e modernização do setor. A primeira delas resultou na criação do SINDGNAISSES no final da década de 1990, objetivando reunir e representar os produtores locais. Estima-se que existam 100 pedreiras e 40 serrarias 
associadas.

Posteriormente, a assinatura do TAC trouxe novas possibilidades para a região. Como por exemplo, a instalação da Argamil em Santo Antônio de Pádua, que emprega mão-de-obra local e utiliza os rejeitos oriundos da exploração de rochas para a fabricação de argamassa. A implantação dos tanques de decantação (Figura 2A) permite a reutilização da água dentro das serrarias, diminui a retirada de água e o despejo de rejeitos no Rio Pomba que causa assoreamento e poluição. O uso, ainda que pequeno, da máquina de fio diamantado diminui a geração de rejeitos no momento da exploração e a utilização de explosivos e, consequentemente, todos os prejuízos ambientais causados pelo uso excessivo e indiscriminado destes, garantindo maior segurança ao trabalhador.

Além dos rejeitos finos gerados no beneficiamento, os grossos também causam danos ao meio ambiente. A área de refugo, que rodeia a frente de lavra, serve como local de despejo do material sem valor comercial. Essa prática gera um problema ambiental local, pois modifica ainda mais a paisagem e pode causar o assoreamento de corpos hídricos. Em Santo Antônio de Pádua os rejeitos grossos gerados na extração das rochas têm sido utilizados na fabricação de brita para a construção civil.

O desconhecimento sobre o processo de legalização e a falta de recursos necessários para promover as mudanças exigidas pelos órgãos fiscalizadores, inviabilizam a maior adesão dos proprietários ao TAC. O baixo investimento destinado ao setor mineral colabora para essa realidade, que dificulta também o acesso aos estabelecimentos, pois temem a fiscalização.

Nos últimos anos as atividades foram suspensas duas vezes devido ao não cumprimento das leis ambientais e trabalhistas. O uso obrigatório de equipamentos básicos de segurança, tanto na exploração quanto no beneficiamento ainda não foi totalmente aceito. Geralmente, é a causa de desentendimento entre patrões que tentam atender as exigências de segurança e empregados, que alegam que alguns deles prejudicam seu desempenho (Figura 2B e C).

Em Santo Antônio de Pádua a exploração de rochas é uma tradição familiar, muitas empresas passaram de uma geração para outra. Em alguns casos a pedreira não é de propriedade da empresa mineradora e, nesse caso, faz-se alocação integral da área onde se desenvolve a mineração, tendo posse apenas da rocha através do direito de exploração do subsolo concedido pelo DRM, necessário também aos empresários proprietários do solo.

O granulito milonitizado se destaca no mercado por causa da sua grande variedade de cores, pouca resistência ao processo de beneficiamento, baixo custo, versatilidade e pode ser aplicado tanto na forma rústica quanto polida. Comercialmente, estas rochas são conhecidas como pedra Olho-de-Pombo, Pinta Rosa, Granito Fino, Pedra Madeira amarela, Pedra Madeira Rosa, Pedra Madeira Branca e Pedra Madeira Branca Codorna (Figura 3).

A extração mineral no município de Italva começou na década de 1930 e adequava-se ao contexto industrial da época. A exploração e o beneficiamento do mármore e a extração do calcário para fabricação do cimento e corretivo de solo atraiu empresas de pequeno, médio e grande porte para a região. Surgiram outras atividades como as marmorarias, fábricas de cimento e comércio local que aumentaram a renda municipal e geraram inúmeras oportunidades de trabalho, contribuindo para o desenvolvimento econômico municipal. Entretanto, um período de desvalorização do setor e a descoberta de jazidas de mármore de maior qualidade na região de Cachoeiro de Itapemirim (ES) fez com que a exploração em Italva fosse diminuindo gradativamente. A 
empresa IMIL, por exemplo, no ano de 2009 empregava 64 funcionários e em anos anteriores chegou a ter 102. Atualmente essa empresa emprega apenas 10 funcionários.

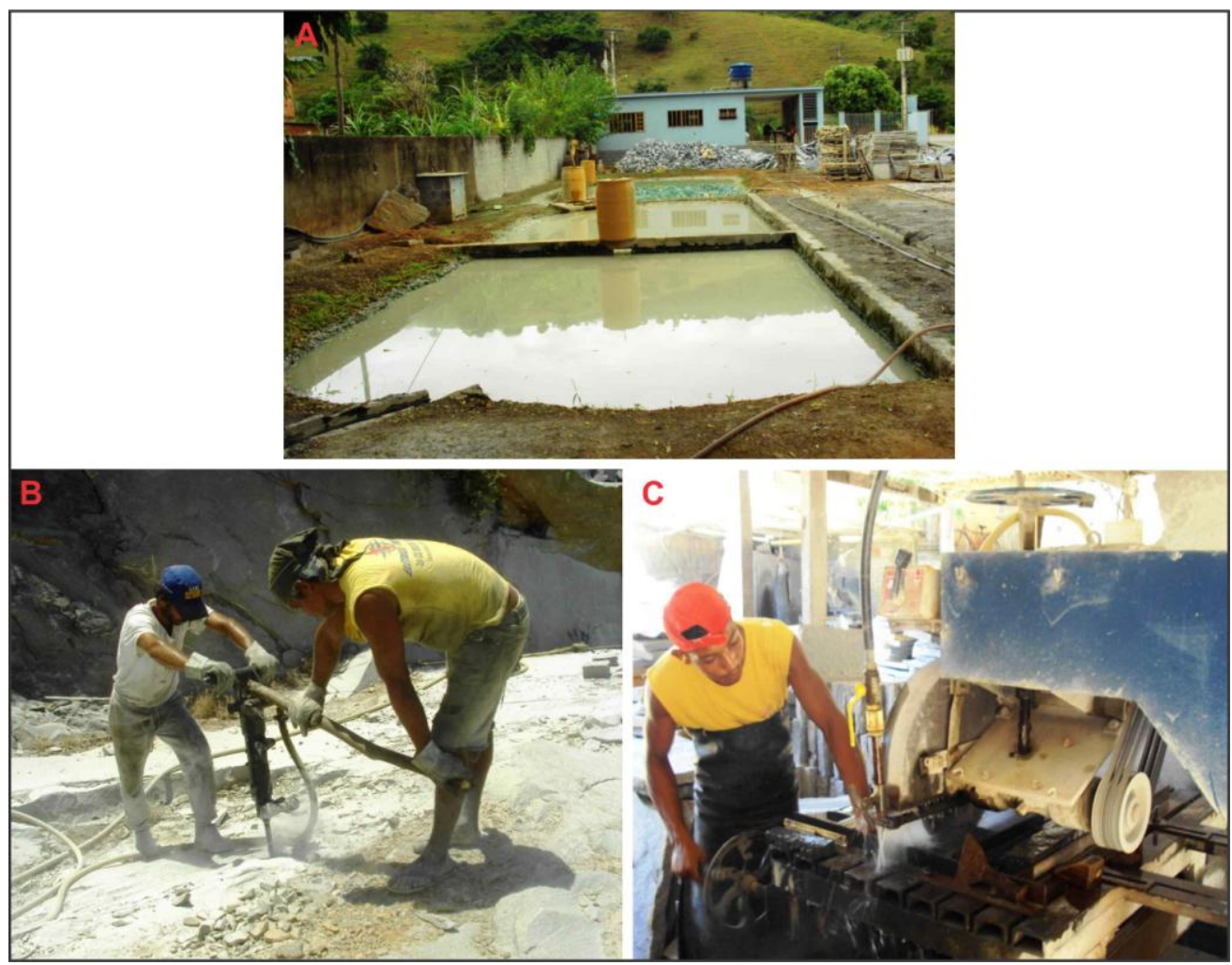

Figura 2: A - Tanque de decantação. B (pedreira) e C (serraria) - Os trabalhadores geralmente não utilizam os equipamentos de segurança na produção de rochas em Santo Antônio de Pádua. Fotos Silvestre, 2010.

A exploração do Mármore Branco Italva (Figura 4A) ocorre majoritariamente através do uso de máquinas com fio diamantado. Em seguida, no beneficiamento os blocos de mármore são subdivididos em chapas, polidos e posteriormente comercializados. O processo produtivo de corretivo para solo envolve as etapas de detonação, britagem, moagem, embalagem e transporte. Atende ao setor agrícola e industrial, principalmente nos estado do Rio de Janeiro e Minas Gerais.

Os principais problemas identificados em Italva foram o abandono das crateras de lavra que acumulam água imprópria para consumo, devido à grande quantidade de cálcio dissolvido (Figura 4B); os resíduos finos que poluem o ar e os grossos que são descartados em locais impróprios (Figura 4C); as rachaduras nas residências (Figura 4D); os tremores e ruídos estão entre as principais reclamações da população que reside próximo às empresas; migração, principalmente para Cachoeiro de Itapemirim (ES), da mão-de-obra com experiência na mineração, por causa do fechamento das empresas tradicionais; e grande parte dos jovens vão para outras cidades, como Macaé, em busca de melhores condições de renda e trabalho. As empresas que permaneceram são de médio a pequeno porte, empregam um número pequeno de trabalhadores e geralmente oferecem baixos salários. Entre as empresas localizadas em Italva, 11 são cadastradas na prefeitura, 10 no DRM, 4 no DNPM e apenas 1 no INEA (Tabela 1). Nem todas estão em atividade e somente 3 estão cadastradas nas três primeiras instituições. 


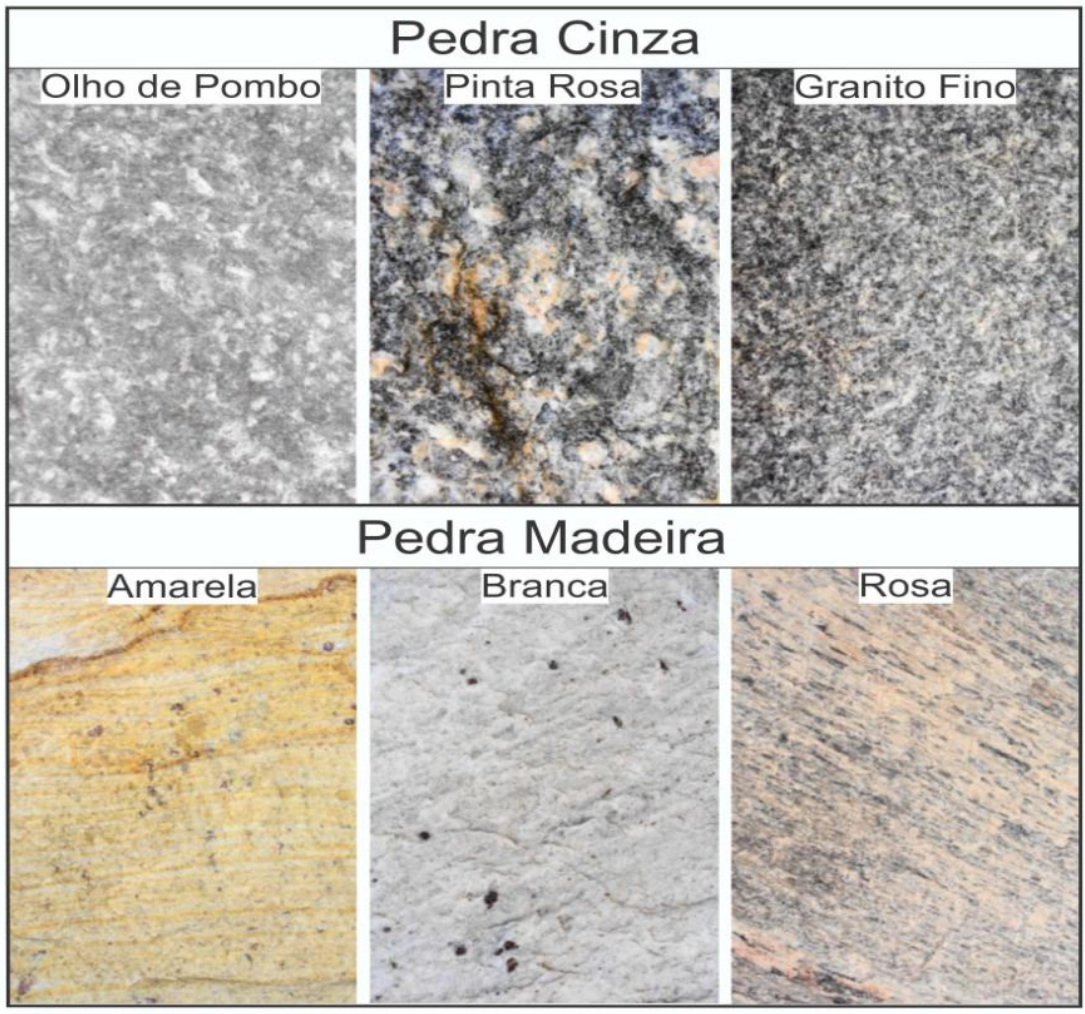

Figura 3: Variedade Litológica de St. ${ }^{\circ}$ Ant. ${ }^{\circ}$ de Pádua. Fotos Silvestre, 2010.

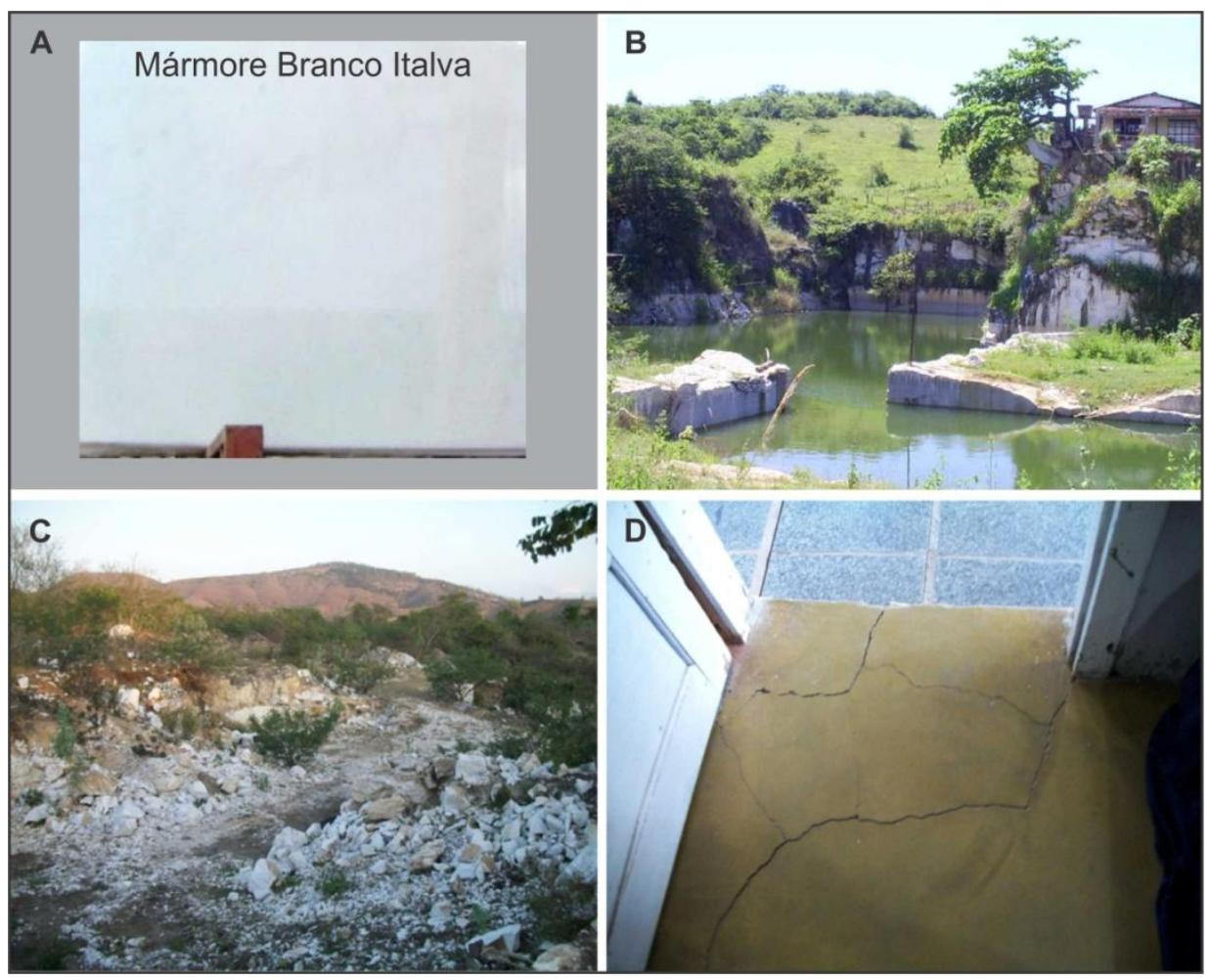

Figura 4: A - Mármore Branco explorado em Italva. B, C e D - Principais problemas associados à produção do mármore no município de Italva. Fotos B, C e D Melo, 2010. 
Tabela 1: Empresas cadastradas na Prefeitura, DRM e DNPM em Italva (Modificada de MELO, 2010).

\begin{tabular}{|c|c|c|c|}
\hline EMPRESAS & PREFEITURA & DRM & DNPM \\
\hline Amilton Dutra Leal & Sim & Não & Não \\
\hline CALPAR Italva Mineração Ltda. & Sim & Não & Não \\
\hline Empresa de Assist. Técnica e Extração Mineral Rural & Sim & Não & Não \\
\hline Enrico Guarneri Ind. e Com. Ltda. & Sim & Não & Sim \\
\hline IMBEG- Imbé Engenharia Ltda. & Sim & Não & Não \\
\hline Pedreira Monte Alegre Ltda. & Sim & Não & Não \\
\hline ABRAM Granitos e Mármores Ltda. & Sim & Sim & Não \\
\hline Asa Branca Mármores e Granitos Ltda. & Não & Sim & Não \\
\hline Holcim Brasil S.A. & Sim & Sim & Sim \\
\hline IMIL-Ind. de Mármores Italva Ltda. & Sim & Sim & Sim \\
\hline Ind. e Com.de Cal Maravilha Ltda. & Sim & Sim & Sim \\
\hline Mineração Panamá Ltda. & Não & Sim & Não \\
\hline MINERBRAL-Mineração Branco Aurora Ltda.Me. & Não & Sim & Não \\
\hline Pedreira de Calcário ITA Branca Ltda. & Sim & Sim & Não \\
\hline Riomagran2006 Ext. e Benef. de Mármores e Granitos Ltda. & Não & Sim & Não \\
\hline Veg’s 01 Mineração Exportação Importação Ltda.Me. & Não & Sim & Não \\
\hline
\end{tabular}

Os resíduos da produção do mármore não possuem um destino adequado, exceto quando são utilizados na produção de calcário para corretivo de solo. Entretanto, um projeto socioambiental desenvolvido pela empresa Calpar Italva Mineração Ltda. em parceria com uma escola estadual, por exemplo, promove o plantio de hortaliças numa estufa para consumo e revenda, além de palestras em prol do meio ambiente. Iniciativas como essa são importantes para a formação de uma sociedade consciente de seus direitos e praticante de seus deveres com a sociedade e com o meio ambiente.

\section{CONSIDERAÇÕES FINAIS}

A exploração de rochas ornamentais tem grande importância socioeconômica no Noroeste Fluminense, pois existem cerca de 300 microempresas e seis mil pessoas empregadas, destas apenas 100 pedreiras e 40 serrarias são associadas ao sindicato local. Trata-se de um setor que vem buscando se desenvolver e se modernizar frente às novas exigências ligadas a produção e comercialização desse recurso natural, apesar do número expressivo de empreendimentos atuando ilegalmente. A modernização e a ampliação do setor representam uma possibilidade de expansão das atividades econômicas direta e indiretamente ligadas ao setor mineral. Desde que as parcerias público-privada (empresas, SINDGNAISSES, SEBRAE, DRM, CETEM, DNPM entre outros) sejam contínuas e capazes de contemplar os microempresários, cuja dificuldade de ajustamento é sempre maior.

A atividade mineradora passa por momentos diferentes nesses municípios. Italva teve a extração de mármore paralisada e hoje se concentra na exploração de dolomita e calcita para a fabricação de corretivo de solo e pó industrial. Por outro lado, Santo Antônio de Pádua passa por um processo de adequação as exigências 
ambientais e trabalhistas para que haja o crescimento do setor. As empresas que não colaboram para o desenvolvimento mineral sustentável impedem melhores resultados, pois continuam desrespeitando as leis ambientais e trabalhistas, comprometendo os recursos regionais e a visão do mercado consumidor sobre a exploração mineral e os impactos ambientais decorrentes da mesma.

\section{AGRADECIMENTOS}

Agradecimentos especiais às diversas instituições e estabelecimentos que contribuiram para a realização deste trabalho (DRM-RJ, DNPM, Argamil, GeoEstação, Map’s Pedras, Comércio de Pedras Paraíso, SEBRAE, SINDGNAISSES e prefeiruras municipais). O presente estudo integra resultados obtidos ao longo das monografias desenvolvidas junto ao Departamento de Geografia da FFP-UERJ sobre a exploração de rochas ornamentais nos municípios de Santo Antônio de Pádua e Italva.

\section{REFERÊNCIAS}

ALMEIDA, S. L. M.; CAMPOS, A. R.; ALBUQUERQUE, G. de A. S. C.; SILVA, M. A. R.; MAIA, M. S. “Pedreiras de Santo Antonio de Pádua-RJ” In: XVII Encontro Nacional de Tratamento de Minério e Metalurgia Extrativa, I Seminário de Química de Colóides Aplicada à Tecnologia Mineral - São Paulo: 1998. p. 135-145.

BAPTISTA FILHO, J. \& TANAKA, M. D. “Caracterização econômica e mercadológica da região produtora de rochas ornamentais de Santo Antônio de Pádua (RJ)”. In: Anuário do Instituto de Geociências - UFRJ; Vol. 25, Rio de Janeiro: 2002a.

BAPTISTA FILHO, J. \& TANAKA, M. D. “Considerações geológicas e Sobre o Parque Produtor de Rochas Ornamentais no Município de Santo Antônio de Pádua - RJ” In: Anuário do Instituto de Geociências - UFRJ; Vol. 25, Rio de Janeiro: 2002.

BATISTA, J. J.; GOMES, B. S.; MARCHETTO, C. M. L.; COSTA, L. A. M. da. Estado do Rio de Janeiro. Secretaria de Estado de Industria, Comercio e Turismo. Departamento de Recursos Minerais. Projeto Carta Geológica do Estado do Rio de Janeiro Folha de Italva. Relatório final - Anexos Volume I e III, 2010.

BOCLIN, H. P. S. “Os impactos dos Arranjos Produtivos Locais - APLs de confecção em Nova Friburgo e rochas ornamentais em Santo Antônio de Pádua na economia do Estado do Rio de Janeiro". Dissertação de Mestrado apresentada ao Programa de Pós-Graduação e Pesquisa em Administração e Economia das Faculdades Ibmec. Rio de Janeiro: 2009. 84p.

BRITTO, J. N. de P.; VARGAS, M. A. \& CARVALHO, G. N. P. de. "Políticas para arranjos produtivos locais no Estado do Rio de Janeiro: aspectos conceituais, institucionalidade e perspectivas de desenvolvimento In: CAMPOS, R. R. C.; STALLIVIERI, F.; VARGAS, M. A. \& MATOS, M. (org.)/E-papers Serviços Editoriais Ltda. - Rio de Janeiro, 2010. p. 215-255.

CARVAlHO, E. A. de; CAMPOS, A. R. de; PEITER, C. C.; ROCHA, J. C. da. “Aproveitamento dos rejeitos 
finos das serrarias de Santo Antônio de Pádua/RJ" In: III SRON - Simpósio de Rochas Ornamentais do Nordeste. Recife, 2002.

CHIODI FILHO, C. "Situação e Perspectivas Brasileiras no Setor de Rochas Ornamentais e de Revestimento" In: "I Simpósio Brasileiro de Rochas Ornamentais; II Seminário de Rochas Ornamentais do Noroeste", 28 nov. 01 dez. 2001, Salvador. Rio de Janeiro: CETEM / MCT, 2002. p. 2-12.

CHIODI FILHO, C. \& CHIODI, D. K. "Relatório Técnico 33 - Perfil de Rochas Ornamentais e de Revestimento" Ministério de Minas e Energia (MME). Secretaria de Geologia, Mineração e Transformação Mineral (SGM). Jmendes Consultoria. 2009. 101p.

DEPARTAMENTO DE RECURSOS MINERAIS (DRM-RJ). "Mapa simplificado do Estado do Rio de Janeiro - As rochas nos cotam sua história...” Projeto Caminhos Geológicos, março de 2008.

DEPARTAMENTO DE RECURSOS MINERAIS (DRM-RJ) - Governo do Estado do Rio de Janeiro (SEDEIS). "Delimitação de área de denominação de origem da região Pedra Carijó Rio de Janeiro/Pedra Cinza Rio de Janeiro/Pedra Madeira Rio de Janeiro" - 06/08/2010.

DEPARTAMENTO DE RECURSOS MINERAIS (DRM-RJ) - Secretaria de Estado de Desenvolvimento Econômico, Energia, Industria e Serviços. Panorama Mineral do estado do Rio de Janeiro - Rio de Janeiro, RJ: 2012. 259p.

ESTATUTO DO SINDGNASSE - Sindicato de Extração e Aparelhamento de Gnaisses no Noroeste do Estado do Rio de Janeiro/RJ. $3^{\circ}$ Alteração Estatutária. Fundado em: 30/10/1998.

ERTHAL, F.; DOURADOS, F.; PALERMO, N.; GUIMARÃES, P. V.; MAURÍCIO, R. da C. \& SANTOS, R. A. dos S. "Diretrizes Públicas para uma mineração sustentável no Estado do Rio de Janeiro". Convênio MME / SGM N 002 de 2006. DRM-RJ Serviço Geológico do Estado do Rio de Janeiro Relatório Final. Rio de Janeiro, 2008

FONTES, A.; VELLOSO, M. \& DIOGO, P. N. “A estratégia de desenvolvimento local proposta pelo Programa Comunidade Ativa: potencialidades e entraves do DLIS". Rio de Janeiro, 2002

MARGUERON, C. \& MELLO, E. F. "Estratégias competitivas para empresas de rochas ornamentais na região metropolitana do Rio de Janeiro" In: Anuário do Instituto de Geociências - UFRJ Vol. 28. 02 /2005. p. 71-101.

MARTINEZ, C. \& HEIDER, M. "Rochas ornamentais e de revestimentos" In: LIMA, T. M. \& NEVES, C. A. R. - Departamento Nacional de Produção Mineral. Sumário Mineral/Ministério de Minas e Energia, Departamento Nacional de Produção Mineral. - Brasília : DNPM/DIPLAM, 2012. 126p. 
MEDINA, H. V. de; PEITER, C. C. \& DEUS, L. A. B. "A cadeia produtiva de rochas ornamentais em Santo Antônio de Pádua." Comunicação Técnica ao XXIII ENEGEP - Encontro Nacional de Engenharia de Produção, Ouro Preto, Escola de Minas da UFOP, 21-24 outubro, 2003 (CD-ROM). 10p. Rio de Janeiro: CETEM, 2003.

PEITER, C. C. \& CHIODI FILHO, C. "Rochas Ornamentais no século XXI: bases para uma política de desenvolvimento sustentado das exportações Brasileiras” - Rio de Janeiro - CETEM/ABIROCHAS, 2001. Disponível em: http://www.abirochas.com.br/livro.php. Acessado em 02/05/2010.

PEITER, C. C. “Abordagem participativa na gestão de recursos minerais: o caso de pedreiras de rochas ornamentais" In: “I Simpósio Brasileiro de Rochas Ornamentais; II Seminário de Rochas Ornamentais do Noroeste”, 28 nov.-01 dez. 2001, Salvador. Rio de Janeiro: CETEM / MCT, 2002. p. 82-88.

PEITER, C. C.; CAMPOS, A.; CARVALHO, E. A. de; GAMEIRO, M. M. M. “Arranjos Produtivos Locais do setor de rochas ornamentais e a experiência do pólo de Santo Antônio de Pádua - RJ” In: IBEROEKA en Mármoles y Granitos. Salvador: 2003. p. 201-218.

PEITER, C. C.; CARRISSO, R. C. C. \& PIRES, D. C. B. “O Arranjo Produtivo Local de Santo Antônio de Pádua (RJ)” In: Recursos Minerais \& Sustentabilidade Territorial: arranjos produtivos locais. Eds.

FERNANDES, F. R. C.; ENRÍQUEZ, Ma . A. R. da S.; ALAMINO, R. de C. J. - Rio de Janeiro: CETEM/MCTI, 2011. V. II. 180p.

RIBEIRO, R. C. da C.; CORREIA, J. C. G.; SEIDL, P. R.; ALMEIDA, S. L. M. de; CARVALHO, E. A. “Utilização de rejeitos de rochas ornamentais em misturas asfálticas”. Rio de Janeiro: CETEM/MCT, 2007. 42p. (Série Tecnologia Mineral, 87).

Termo de Compromisso de Ajustamento de Conduta Coletivo - Empresas de Extração, 2004. Disponível em: http://4ccr.pgr.mpf.gov.br/atuacao-do-mpf/tacprocedimentos/docs_tacs/integra_tacs/TAC\%20EXTRACaO\%20MINERAL\%20RJ.pdf Acessado em 02/05/2009.

VARGAS, T.; MOTOKI, A.; NEVES, J. L. P. "Rochas ornamentais do Brasil, seu modo de ocorrência geológica, variedade tipológica, explotação comercial e utilidades como materiais nobres de construção.” Revista de Geociências, Niterói - RJ, v. 2, n. 2, 2001. p. 119-132.

ZEPEDA, Vinicius. "Novos produtos deverão impulsionar setor de rochas ornamentais”. 2009. Disponível em: http://www.faperj.br/boletim interna.phtml?obj_id=5886. Acessado em 05/09/2012.

IBGE, Instituto Brasileiro de Geografia e Estatística. Santo Antônio de Pádua. In: IBGE Cidades. Disponível em: http://www.ibge.gov.br/cidadesat/topwindow.htm?1 Acessado em 03/09/2012. 